\title{
Study on Dynamic Mechanical Properties of Limestone under Uniaxial Impact Compressive Loads
}

\author{
Fei Zou, ${ }^{1,2,3}$ Zheng-feng Fang, ${ }^{1}$ and Ming-yao Xia ${ }^{2}$ \\ ${ }^{1}$ Guizhou Transportation Planning Survey \& Design Academy, Guiyang, Guizhou 550081, China \\ ${ }^{2}$ School of Civil Engineering, Central South University, Changsha, Hunan 410075, China \\ ${ }^{3}$ Construction Engineering Quality Supervision Bureau of Guizhou Province, Guiyang, Guizhou 550000, China
}

Correspondence should be addressed to Ming-yao Xia; xiamingyao@csu.edu.cn

Received 3 May 2016; Accepted 30 October 2016

Academic Editor: Gregory Chagnon

Copyright (C) 2016 Fei Zou et al. This is an open access article distributed under the Creative Commons Attribution License, which permits unrestricted use, distribution, and reproduction in any medium, provided the original work is properly cited.

\begin{abstract}
The dynamic mechanical properties of limestone are studied with 5 types of impact pressure acting on limestone samples in axial direction in this paper. The rubber shaper with a diameter of $5 \mathrm{~mm}$ and thickness of $2 \mathrm{~mm}$ is adopted. Besides the conical punch of split pressure bar of Hopkinson with a diameter of $50 \mathrm{~mm}$ is also used. The half-sinusoid pulse is obtained by using the pulse shaper method and special punch method; the constant strain rate deformation of the sample is realized. Dynamic compressive properties and failure modes of limestone under different impact pressure are investigated. In addition, energy dissipation is studied in the process of experiment. The results show that the dynamic compressive strength of limestone has an exponent relation to strain rate. The failure strain, degree of fragmentation, incident energy, and absorption energy increase, while the energy absorbency decreases with the increasing of strain rate. However, the initial elastic modulus is not sensitive to the strain rate. The research method and conclusions have reference value for the dynamic mechanical properties of other brittle materials.
\end{abstract}

\section{Introduction}

With the increasing of infrastructure construction and rapid development of the urbanization, there will be many huge projects accompanied with a large number of blasting construction works. In engineering practice, most of rock mass will be affected by dynamic loads in the process of damage; the investigation on dynamic performance of the rock material under impact load is particularly important [1-4]. The split Hopkinson pressure bar (SHPB) is widely used in this research $[5,6]$. However, the pulse stress wave generated by the traditional SHPB apparatus is high frequency oscillation of square wave and rises in a short time; the samples have always been destroyed before the internal stress balance has been reached and are unable to meet the requirements of the sample uniform deformation. In addition, the strong dispersion effect of traditional SHPB apparatus will make the test data fluctuate largely.

To solve the problems of the above SHPB apparatus, in 1984, Frantz et al. [7] affixed metal gaskets to the end surface of the incident bar, which is waveform shaper, successfully reduced the dispersion effect, improved the rising edge of the incident wave, and accelerated the stress balancing process of the sample. In 1993, Xibing and Desheng [8] replaced the traditional loaded rectangular wave with half-sine-load of cone-shaped punch and successfully removed the P-C oscillation. Meanwhile, Zhou et al. [9] got different shapes of incident stress pulse waveform with different forms of bullets and a half-sine wave which reduces the dispersion and oscillation of the wave when propagating along the rod and keeps the stress in sample evenly. At present, these methods have been widely used in the study of the dynamic characteristics of engineering materials under high strain rate like rocks, ceramics, and composites. Friedman et al. [10] and Janach [11] used this technology to do uniaxial compression experiments for granite and limestone with SHPB experimental apparatus; the strain rate ranges from $10^{1}$ to $10^{3}$. The experimental results show that the dynamic elastic modulus and compressive strength of the two kinds of rocks increase with the increasing of strain rate, the dynamic compressive strength of rock material is much greater than the static load strength, and the extent of breaking rock 
material increases with the increasing of strain rate. Leblanc and Lassila [12] described an experimental method based on the SHPB technique which allows dynamic tensile testing of $1.0 \mathrm{~mm}$ thick sheet material. Li et al. [13] proposed a micromechanics-based model to study the mechanical properties of granite under dynamic uniaxial compressive loads; a constitutive relation of the granite is derived from the energy equilibrium equation and correlated with the experimental results. Meng and $\mathrm{Li}$ [14] used split Hopkinson pressure bar (SHPB) to measure the uniaxial compressive stress-strain relation of various engineering materials at high strain rate. Li et al. [15] used the pressure bar technique of Hopkinson to study the dynamic characteristics and the failure modes of various rock materials. Liu et al. [16] used the split Hopkinson pressure bar (SHPB) test apparatus with a diameter of $100 \mathrm{~mm}$ and the thin circular copper sheet as a waveform shaper; the amphibolite samples were impacted in axial direction at different speed to test their dynamic mechanical properties in strain rate which ranges from 40 to 150 . The results show that dynamic strength enhancement factor of the amphibolite and average strain rate of logarithm had approximately linear relationship; the compressive strength and specific energy absorption increase with the increasing of average strain rate. Meanwhile, it is found that the failure strain of rock sample increases basically with the increasing of strain rate, which shows significantly strain rate dependence. But its initial elastic modulus is not sensitive to the strain rate.

Limestone is a kind of extremely common rock in Guizhou mountainous area; the study on its dynamic mechanical properties not only improves dynamic research of the rock but also has significant value for practical engineering, such as blasting construction, road construction, and other engineering works in limestone mountainous area [17-22]. The dynamic mechanical properties of limestone are investigated under different impact loads in this paper, using the rubber with diameter of $5 \mathrm{~mm}$ and thickness of $2 \mathrm{~mm}$ as a waveform shaper SHPB system and 5 different types of impact pressure on the limestone in axial direction. The research results have certain significance in guiding the actual engineering construction in Guizhou mountainous area.

\section{Dynamic Impact Compression Test of Rock}

2.1. Preparation and Basic Mechanical Properties of Rock Samples. Rocks with better integrity and homogeneity as research objects were selected from the Guian highway blasting site. In order to reduce the dispersion of samples and avoid the differences of samples in the composition and structure, the samples are taken from the same rock mass. Therefore, the differences of chemical composition and density of the samples are negligible. The samples are processed into cylinder with diameter of $50 \mathrm{~mm}$ and thickness of $35 \mathrm{~mm}$. According to the requirements of rock mechanics tests, each sample end surface and cylindrical surface should be carefully polished to ensure that the nonparallelism degree of both ends is less than $0.02 \mathrm{~mm}$ and the not-perpendicularity degree of circumference and end surface is less than $0.02 \mathrm{~mm}$. The test samples are shown in Figure 1. The limestone with the color of gray is
TABLE 1: The mineral composition of limestone samples.

\begin{tabular}{lcccc}
\hline Name & \multicolumn{3}{c}{ Calcite Dolomite Quartz powder $\begin{array}{c}\text { Clay } \\
\text { minerals and } \\
\text { others }\end{array}$} \\
\hline Composition (\%) & 85 & 8 & 4 & 3 \\
\hline
\end{tabular}

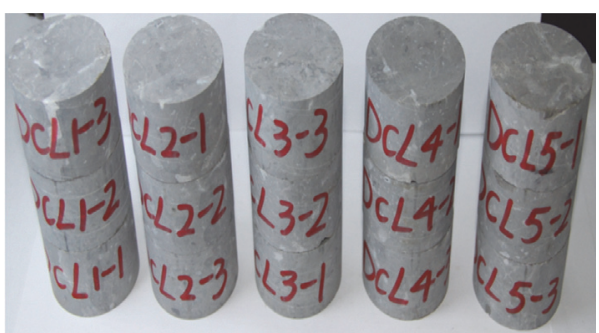

FIGURE 1: Limestone samples under impulsive compression.

mainly composed of calcite and dolomite and contains a small amount of quartz powder, clay minerals, organic impurities, and so on. The rock is homogeneous without visible defects in the naked eye; the main mineral components are calcium carbonate and magnesium carbonate; intense bubbles are observed in the reaction with dilute hydrochloric acid. The mineral composition and physicomechanical properties of limestone samples are shown in Tables 1 and 2, respectively.

The static uniaxial compression test of limestone completes in the RMT-150C system as shown in Figure 2.

2.2. The SHPB Impact Compression Test Apparatus and Calculation Principle. The large diameter SHPB device $(50 \mathrm{~mm})$ is adopted in this experiment, which is jointly developed by the Wuhan Geotechnical Institute and University of Science and Technology of China; the schematic diagram is shown in Figure 3. The test system has the characteristic of high strain rate load, which is suitable for the heterogeneous brittle material, and the strain rate of the samples ranges from 10 to $10^{3}$. The main components include driving portion (including pressure cylinders), support portion, lever portion, damping absorbing portion, signal detection, and acquisition and processing section. The diameter of the pressure bar is $50 \mathrm{~mm}$, the impact rod is a $0.4 \mathrm{~m}$ conical rod, and the incident rod and the transmission rod are $2.50 \mathrm{~m}$. The incident rod, the transmission rod, the absorbing rod, and the impact rod use the $35 \mathrm{CrMnSiA}$ alloy steel, the density is $7800 \mathrm{~kg} / \mathrm{m}^{3}$, the longitudinal wave velocity is $5124 \mathrm{~m} / \mathrm{s}$, the elastic modulus is $210 \mathrm{GPa}$, and Poisson's ratio is 0.25 .

Based on the two basic assumptions of SHPB experiment, the dynamic mechanical parameters of the samples, such as the stress $\sigma_{s}(t)$, the strain rate $\dot{\varepsilon}_{s}(t)$, and the strain $\varepsilon_{s}(t)$, are indirectly calculated by the strain gauge pasted in incident rod and transmission rod. 
TABLE 2: Physicomechanical properties of limestone under static loads.

\begin{tabular}{lccccc}
\hline Density $\left(\mathrm{kg} / \mathrm{m}^{3}\right)$ & $\begin{array}{c}\text { Loading rate } \\
(\mathrm{mm} / \mathrm{s})\end{array}$ & $\begin{array}{c}\text { Compressive strength } \\
(\mathrm{MPa})\end{array}$ & Failure strain & $\begin{array}{c}\text { Elastic modulus } \\
(\mathrm{GPa})\end{array}$ & Poisson's ratio \\
\hline 2754.92 & 0.002 & 130.10 & $7.19 E-3$ & 27.13 \\
\hline
\end{tabular}

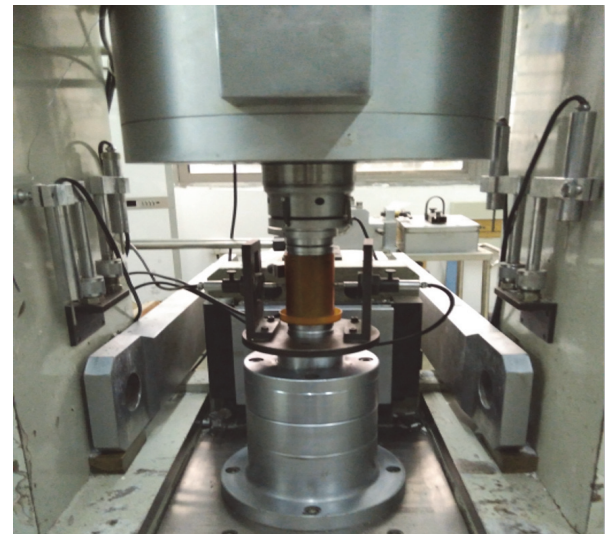

FIGURE 2: Static compression test of limestone.

The calculation formulas are expressed as follows:

$$
\begin{aligned}
& \sigma_{s}(t)=\frac{E A}{2 A_{0}}\left[\varepsilon_{i}(t)+\varepsilon_{r}(t)+\varepsilon_{t}(t)\right], \\
& \dot{\varepsilon}_{s}(t)=\frac{C_{0}}{L_{0}}\left[\varepsilon_{i}(t)-\varepsilon_{r}(t)-\varepsilon_{t}(t)\right], \\
& \varepsilon_{s}(t)=\frac{C_{0}}{L_{0}} \int_{0}^{t}\left[\varepsilon_{i}(t)-\varepsilon_{r}(t)-\varepsilon_{t}(t)\right] d t,
\end{aligned}
$$

where $A$ and $A_{0}$ are cross-sectional area of the sample and the pressure rod, respectively. $E$ is the elastic modulus of the pressure bar; $\varepsilon_{i}(t), \varepsilon_{r}(t)$, and $\varepsilon_{t}(t)$ are the incident strain wave, the reflection strain wave, and the transmitted strain wave which are measured on the incident rod and the transmission rod. $C_{0}$ and $L_{0}$ are the wave velocity and the length of the pressure bar, respectively.

When using the traditional and steeper stress pulse loading, the rise time is short and the shock wave is strong; the stress-strain of the sample cannot be guaranteed to be uniform before the destruction. Here, it is necessary to use the shaper. The rubber sheet is used as a pulse shaper during the test. When the impact of the bullet is strong, the rubber is deformed to filter out the high frequency wave of the incident wave and reduce the waveform dispersion. Meanwhile, the rise time of the incident pulse is prolonged, which is beneficial to achieving the stress balance of the sample.

2.3. Test Program. This experiment selects five groups of samples; each group consists of at least three specimens. The different strain rates are obtained by adjusting the different impact pressure, and impact pressure is $0.1,0.3,0.5,0.7$, and 1.0 $\mathrm{MPa}$, respectively.

During the test, the sample is tightly sandwiched between the incident rod and the transmission rod to ensure that the sample is on the same line with the axis of the pressure bar. The contact surface between the sample and the end surface of the pressure bar is smeared Vaseline to reduce the interfacial friction effect. In order to prevent the sliding of the sample during the test, it can be uniformly applied to the center of the contact surface between the sample and the end surface of the pressure bar.

Before each impact test, make sure that the bullet is in the same position in the firing chamber and the distance from the incident bar remains unchanged. The distance of this test is $53 \mathrm{~cm}$ to ensure the same impact velocity under the same impact pressure.

\section{Experimental Results and Analysis}

3.1. The Waveform Shaping Technique. In order to achieve constant strain rate deformation of the sample in SHPB experiment, the shaper method and shaped punch method $[8,23,24]$ are commonly used. In this experiment, the two methods are synchronously used to obtain the half-sine wave and achieve the constant strain rate deformation of the sample. Figure 4 shows the waveform under different sizes of rubber shaper when playing empty rod [8]. From Figure 4, it can be clearly seen that the original high frequency oscillation of the square wave is modified to be half-sine wave that the ascent is gentler and the waveform is smoother after the addition of the shaper. Through the comparison of the pulse waveform in Figure 4, we can see that the rising time of the rising edge is only $47.10 \mu \mathrm{s}$ and there are oscillations when the waveform shaper is not added; it is difficult to ensure that the sample is uniformly stressed before failure in a short time. When using the shaper with diameter of $5 \mathrm{~mm}$ and thickness of $1 \mathrm{~mm}, 2 \mathrm{~mm}$, and $3 \mathrm{~mm}$, the time of the rising edge is $135 \mu \mathrm{s}, 221.50 \mu \mathrm{s}$, and $274.30 \mu \mathrm{s}$, respectively. Compared to the condition with no shaper, the time of the rising edge increased by $186.62 \%, 370.28 \%$, and $482.38 \%$, respectively. This will make sure the stress pulse has enough time to reflect back, and stress uniform is achieved before the destruction of the sample. On the other hand, under the same loading condition, as the waveform shaper absorbs a part of the energy, the strain rate of the sample is lower than that when the waveform shaper is not added; the corresponding compressive strength of increase value is also reduced relatively. It can be concluded that the maximum voltage value of the incident wave without the shaper is $0.96 \mathrm{~V}$. When using the shaper with diameter of $5 \mathrm{~mm}$ and thickness of $1 \mathrm{~mm}, 2 \mathrm{~mm}$, and $3 \mathrm{~mm}$, the maximum voltage value, which is reduced by $22.92 \%, 30.52 \%$, and $42.08 \%$, decreases by $0.74 \mathrm{~V}, 0.667 \mathrm{~V}$, and $0.556 \mathrm{~V}$, respectively. According to the SHPB test principle, it means that the strain rate of the test specimen will be reduced subsequently. 


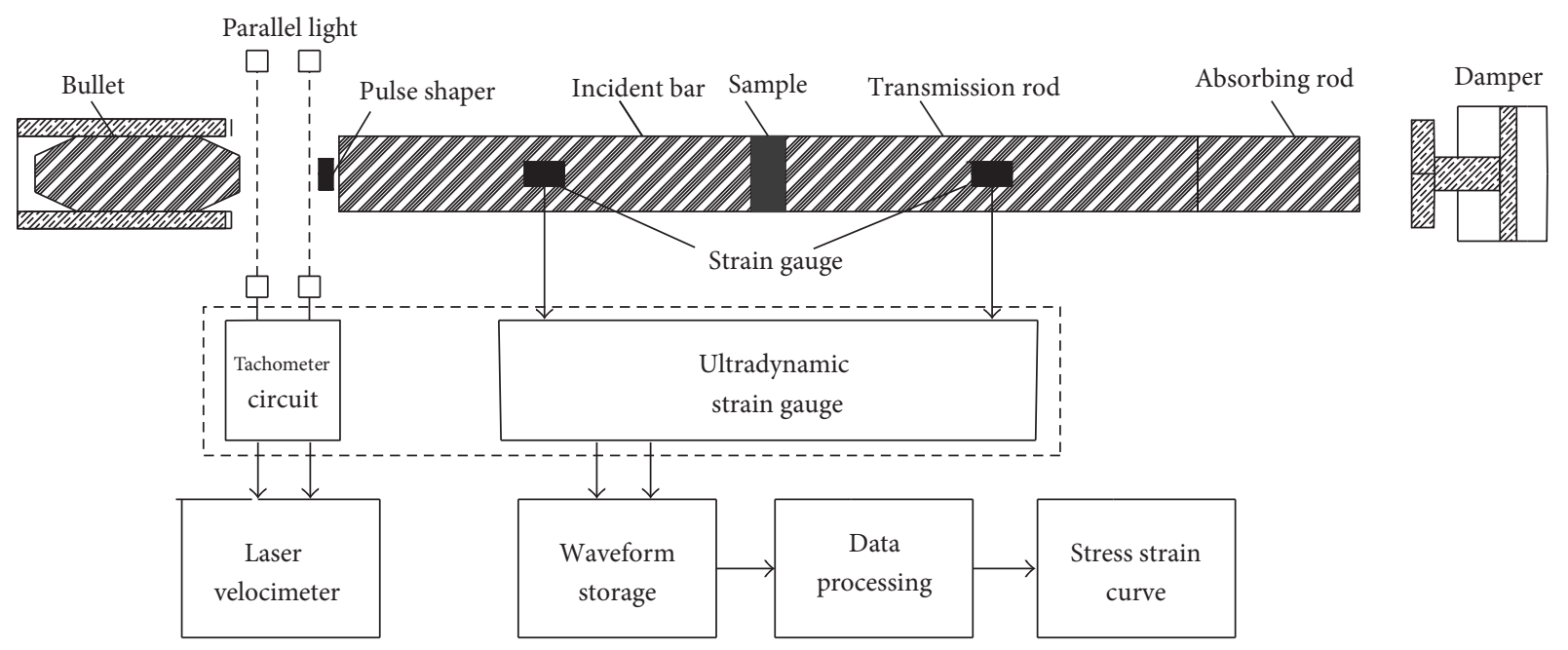

FIGURE 3: Sketch of SHPB apparatus.

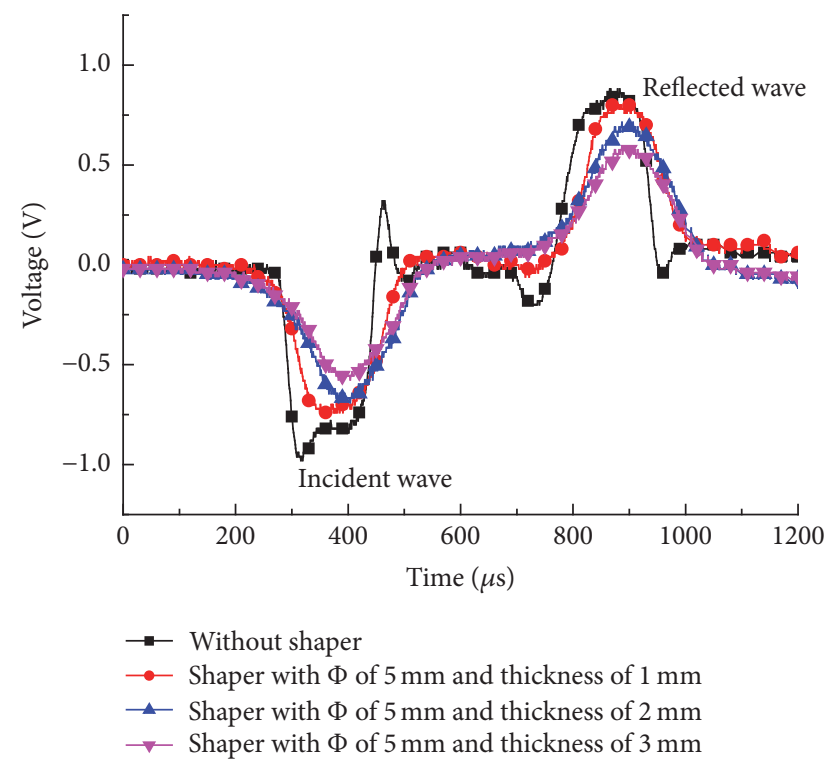

FIGURE 4: The total reflected waves under different sizes of pulse shape.

From Figure 5, it is apparent that parts of the reflected wave do not meet the requirements of SHPB test using the shaper with diameter of $5 \mathrm{~mm}$ and thickness of $1 \mathrm{~mm}$. There is no reflected wave when using the shaper with thickness of $2 \mathrm{~mm}$ and $3 \mathrm{~mm}$, which explains that the shaper can filter out the unwanted reflected wave. Based on the above analysis, the shaper with the diameter of $5 \mathrm{~mm}$ and the thickness of $2 \mathrm{~mm}$ is selected for this experiment. It can not only meet the test of the effectiveness but also ensure the real dynamic mechanical properties of the reaction sample.

3.2. Experimental Procedure and Results. Figure 6 shows the typical half-sine stress waveform when the impact pressure is $0.7 \mathrm{MPa}$. It can be seen that the shapes of the incident wave and the transmission wave are similar and have similar variation laws. As the platform segment of reflected wave exists, it can be considered that the deformation process of the sample occurs under constant strain rate.

Table 3 shows the SHPB test results of limestone under different impact pressure. In consideration of the test differences and the certain dispersion of the rock samples, two similar pieces of test data of samples are selected. We can see from Table 3 that the strain rate, peak strain, and dynamic compressive strength increase significantly with the increasing of impact pressure.

3.3. Dynamic Compression Characteristics and Analysis of Limestone Samples. Figure 7 shows the stress-strain curves of limestone samples under different impact pressures; Figure 8 shows the failure modes of limestone samples under different strain rates. From Figure 7, the initial loading curves of limestone under different impact pressures are coincident. The initial modulus does not change with the increasing of strain rate, and the initial modulus of limestone is not sensitive to the strain rate. Limestone shows obvious linear elastic deformation characteristic in this stage. In the middle and later stages of the loading stage, the loading slope is changed and shows a decreasing trend. Because of that the sample is gradually entering the yield stage with the increasing of the loading stress. The plastic strain resulting by the gradual expansion of internal cracks reduces the ability of the rock to transfer load, and the elastic modulus is also gradually reduced.

Combined with Figures 7 and 8, we can see that the unloading curve of rock shows an obvious elastic hysteresis in the case of low strain rate $\left(=71.50 \mathrm{~s}^{-1}\right)$. At the same time, there is no obvious damage to the limestone samples. With the increasing of strain rate, the failure strain of the samples and the yield strength increase. The fragments scale of sample destruction decreases prominently and the number of fragments increases significantly, which shows more strong strain rate effects. 


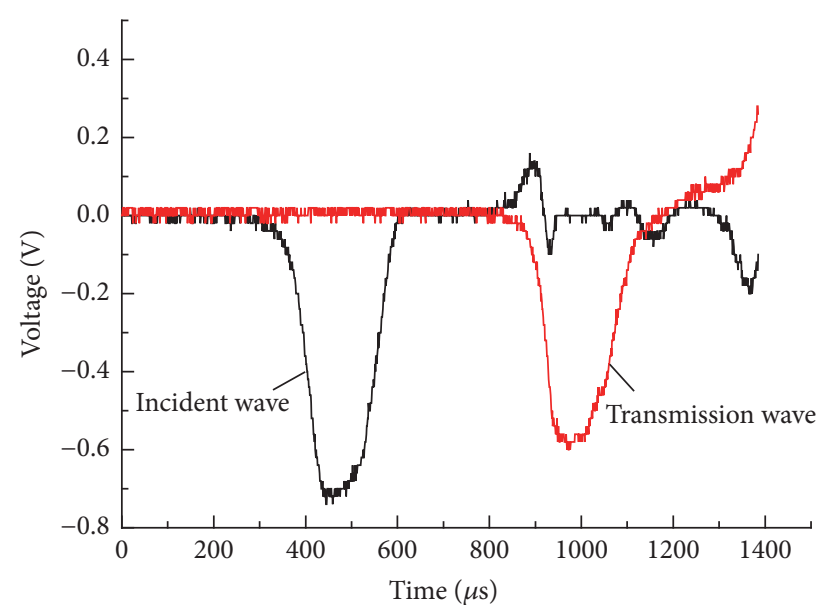

(a) The total transmission waves of shaper with diameter of $5 \mathrm{~mm}$ and thickness of $1 \mathrm{~mm}$

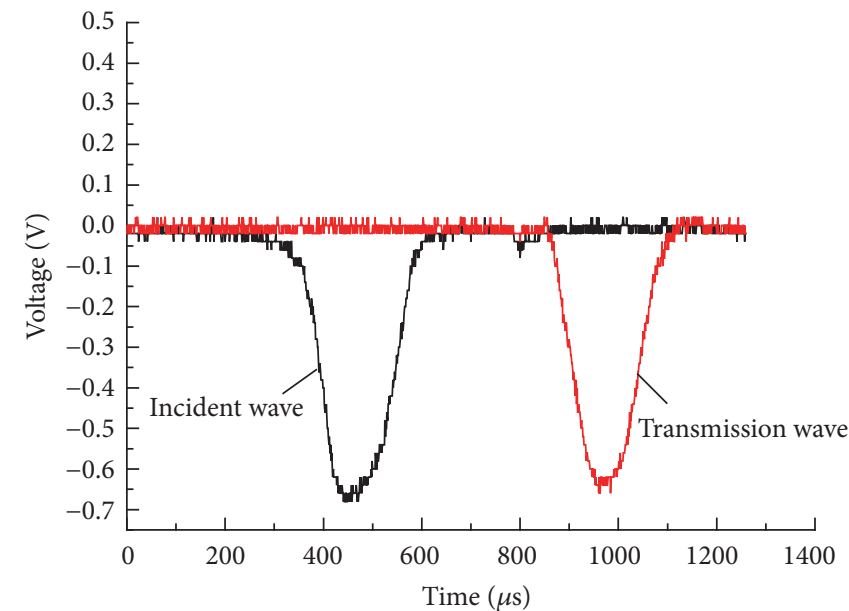

(b) The total transmission waves of shaper with diameter of $5 \mathrm{~mm}$ and thickness of $2 \mathrm{~mm}$

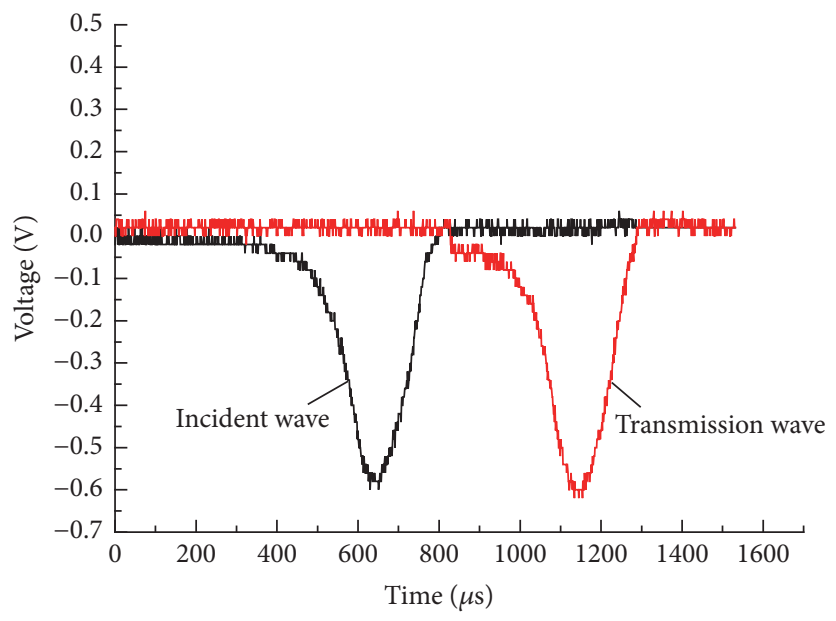

(c) The total transmission waves of shaper with diameter of $5 \mathrm{~mm}$ and thickness of $3 \mathrm{~mm}$

FIGURE 5: The total transmission waves under different sizes of pulse shape.

TABLE 3: Test results of SHPB tests on limestone samples.

\begin{tabular}{|c|c|c|c|c|c|c|}
\hline $\begin{array}{l}\text { Impact } \\
\text { pressure, } p \\
(\mathrm{MPa}) \\
\end{array}$ & Sample numbers & $\begin{array}{c}\text { Sample } \\
\text { thickness/diameter } \\
(\mathrm{mm})\end{array}$ & $\begin{array}{l}\text { Strain rate } \\
\qquad\left(\mathrm{s}^{-1}\right)\end{array}$ & $\begin{array}{l}\text { Dynamic compressive } \\
\text { strength }(\mathrm{MPa})\end{array}$ & $\begin{array}{l}\text { Peak strain } \\
\left(10^{-3}\right)\end{array}$ & $\begin{array}{l}\text { Fragmentation } \\
\text { degree }\end{array}$ \\
\hline \multirow{2}{*}{0.1} & DCL01-1 & $35 / 50$ & 71.50 & 143.56 & 7.09 & Undamaged \\
\hline & DCL01-2 & $35 / 50$ & 74.67 & 152.21 & 7.24 & Penetrating crack \\
\hline \multirow{2}{*}{0.3} & DCL02-1 & $35 / 50$ & 98.78 & 200.14 & 8.02 & Two pieces \\
\hline & DCL02-3 & $35 / 50$ & 104.86 & 189.34 & 8.08 & Two pieces \\
\hline \multirow{2}{*}{0.5} & DCL03-1 & $35 / 50$ & 114.69 & 275.89 & 10.44 & $\begin{array}{l}\text { Three pieces and } \\
\text { fragments }\end{array}$ \\
\hline & DCL03-2 & $35 / 50$ & 124.45 & 281.43 & 10.51 & $\begin{array}{l}\text { Three pieces and } \\
\text { fragments }\end{array}$ \\
\hline \multirow{2}{*}{0.7} & DCL04-2 & $35 / 50$ & 153.73 & 393.47 & 13.02 & $\begin{array}{l}\text { Seven pieces and } \\
\text { fragments }\end{array}$ \\
\hline & DCL04-3 & $35 / 50$ & 156.21 & 390.63 & 13.23 & $\begin{array}{l}\text { Eight pieces and } \\
\text { fragments }\end{array}$ \\
\hline \multirow{2}{*}{1.0} & DCL05-1 & $35 / 50$ & 165.96 & 521.28 & 17.01 & Fragments \\
\hline & DCL05-3 & $35 / 50$ & 173.72 & 514.87 & 17.54 & Fragments \\
\hline
\end{tabular}




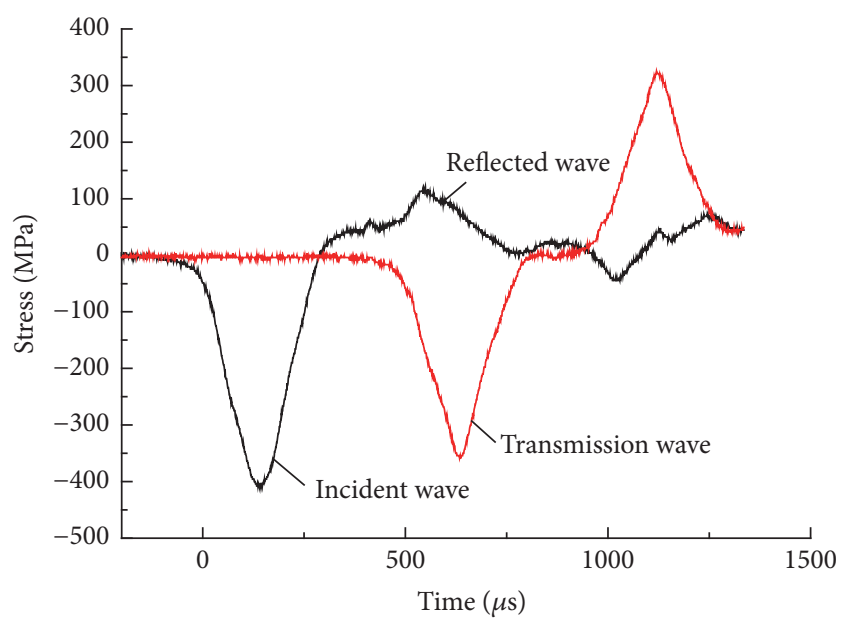

FIgURE 6: Typical waveform of compression test.

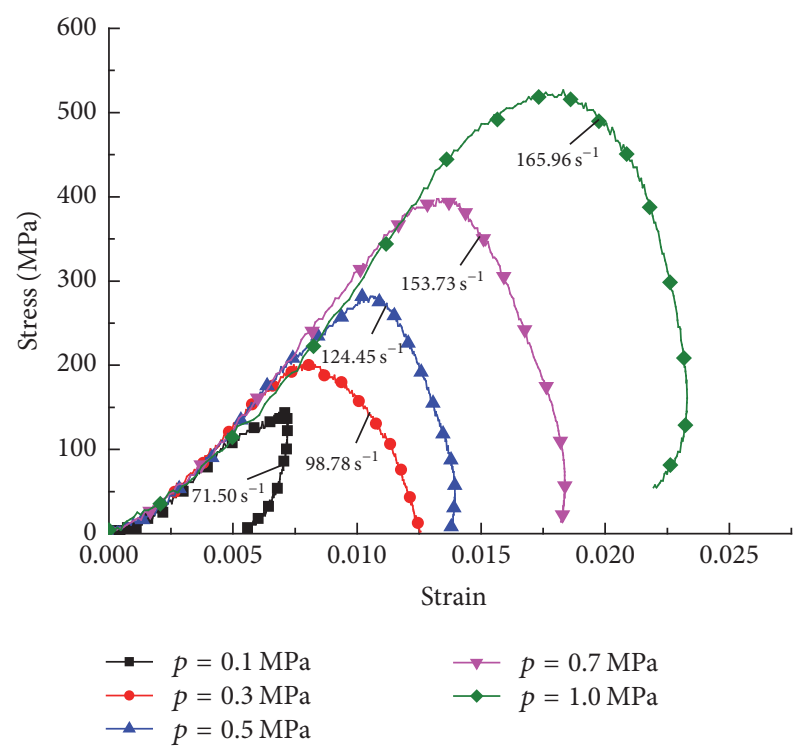

FIGURE 7: Stress versus strain curves of limestone samples under impact loading.

It can also be seen from Figure 8 that the dynamic compressive failure of the limestone samples under the former four strain rates is a significant axial splitting failure mode. When the strain rate is higher, the destruction of limestone shows the crushing failure form which is crushed into numerous small pieces. From the analysis of the microstructural characteristics of the material, the rock material is a kind of typical inhomogeneous brittle material. It contains generally defects in a variety of different scales such as rock particle boundary, holes, cracks, and weak media. When the strain rate is lower, the samples are subjected to uniaxial compressive loads. Cracks are generated from the crack tip of the existing defects, extended parallel to the direction of stress obviously, interconnected, and annexed ultimately. While the new crack is not enough to fully expand through, the size after breaking is larger. When the strain rate
TABLE 4: Equations of fitting curves between dynamic compression strength and strain rate of limestone samples.

\begin{tabular}{llc}
\hline Curve types & Equations of curves & $R^{2}$ \\
\hline Linear & $\sigma_{d}=3.7928-166.12$ & 0.928 \\
Polynomial & $\sigma_{d}=0.0312^{2}-3.6647+250.06$ & 0.985 \\
Logarithm & $\sigma_{d}=410.86 \ln ()-1662.6$ & 0.855 \\
Power & $\sigma_{d}=0.2356^{1.4801}$ & 0.963 \\
Exponential & $\sigma_{d}=54.013$ & 0.992 \\
\hline
\end{tabular}

increases to a certain value $\left(165.96 \mathrm{~s}^{-1}\right)$, the rock absorbs more energy and produces more new crack before the cracking of the microcrack under the low strain rate. These new cracks gradually expand and participate in the crushing process, resulting in a smaller block of rock fragmentation.

As shown in Figure 9, the changes of the dynamic compressive strength of limestone vary with the strain rate. The dynamic compressive strength of limestone increases with the increasing of strain rate, which shows a strong strain rate effect. If only considering the effect of strain rate on the dynamic compressive strength, using the linear, polynomial, logarithmic, power, and exponential five kinds of equations of smooth fitting curves between dynamic compression strength and strain rate in Excel, the results are obtained and are shown in Table 4.

Comparing the correlation coefficients, the dynamic compressive strength of limestone sample has an exponential relationship to strain rate; the resulting correlation coefficient is also the biggest and has a strong correlation, which can be expressed as follows:

$$
\sigma_{d}=54.013 e^{0.0133 \dot{\varepsilon}}\left(R^{2}=0.992\right) .
$$

The strain rate effect of the dynamic compressive strength of limestone can be analyzed from two aspects: the stress state and the relationship of crack propagation and energy. Seen from the stress state, the strain rate hardening effect of rock can be considered as the mechanical response of the material during the state transition from one-dimensional stress to one-dimensional strain state $[25,26]$. Because of the impact load, the lateral deformation of sample is limited by the inertia effect of the materials. The restriction effect increases with the increasing of strain rate, the stress state of rock sample is not one-dimensional stress but approximately passive confining pressure, and the compressive strength increases with the increasing of strain rate. According to the relationship of crack propagation and energy, all kinds of defects and failure of rock sample are reasons of crack generation and propagation. The generation and expansion of internal crack of rock material would consume energy; in particular the generation of new cracks needs more energy than the expansion of internal cracks. Under the low strain rates, the stress wave carries the lower energy. Therefore, the fracture failure of rock material is mainly the propagation and coalescence of the inherent cracks, and only those cracks that consume less energy and destroy the material have a practical effect on the failure of the material. Therefore, the number of cracks that have effect on the failure of the material 


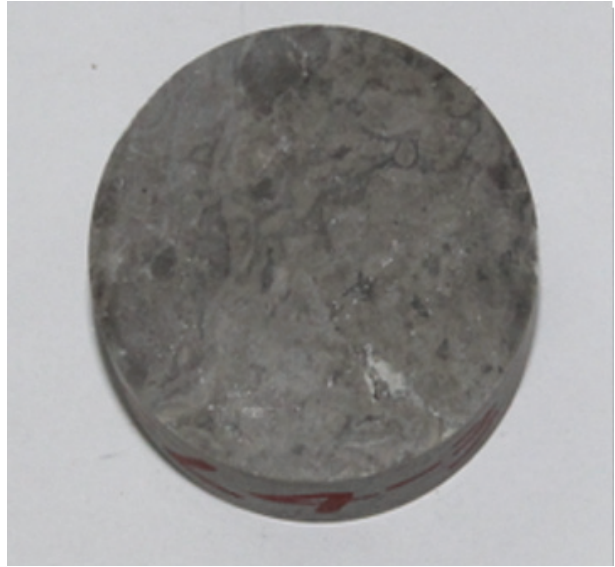

(a) Strain rate, $71.50 \mathrm{~s}^{-1}$

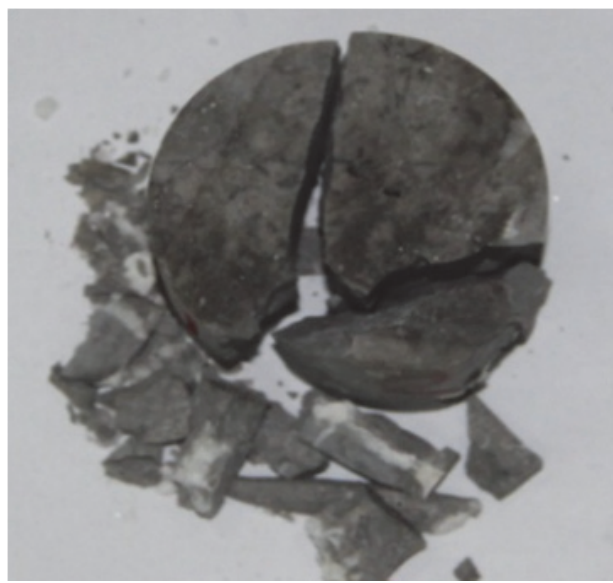

(c) Strain rate, $124.45 \mathrm{~s}^{-1}$

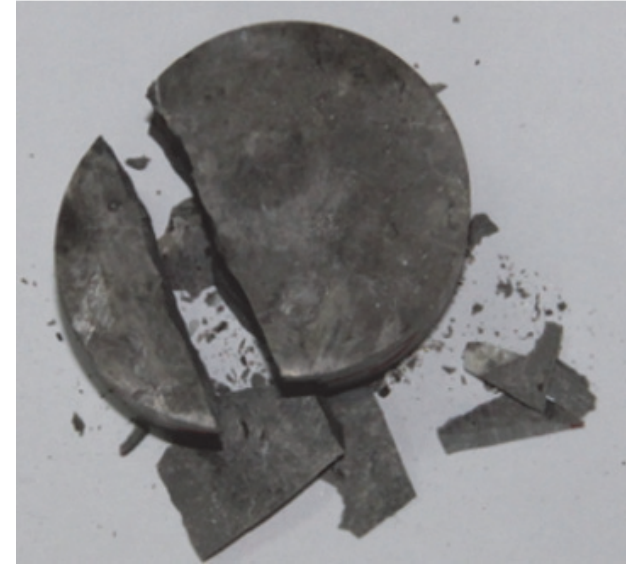

(b) Strain rate, $98.78 \mathrm{~s}^{-1}$

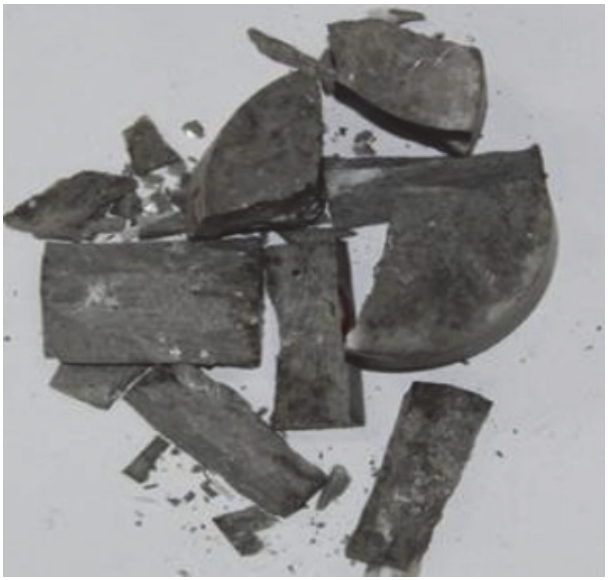

(d) Strain rate, $153.73 \mathrm{~s}^{-1}$

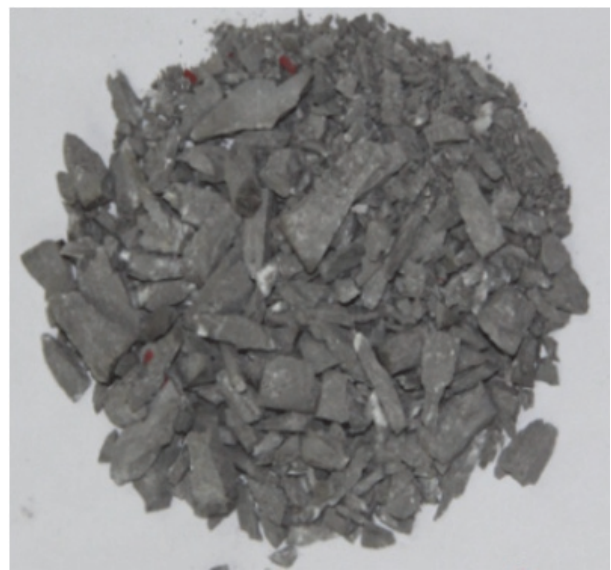

(e) Strain rate, $165.96 \mathrm{~s}^{-1}$

FIgURE 8: Failure modes of limestone with different strain rates.

is small, the size of crushing is large, and the degree of fragmentation is small. The critical stress value of the broken rock is low, resulting in the fact that the rock has a lower compressive strength at low strain rate. With the increasing of the strain rate, the rock material absorbs higher energy in a short time. At lower strain rates, more microcracks can be extended before the cracked microcracks penetrated. Meanwhile, the number of new cracks is increasing, which leads to the reduction of the crushing size of the rock material, the increasing of fragmentation degree, and the higher critical 


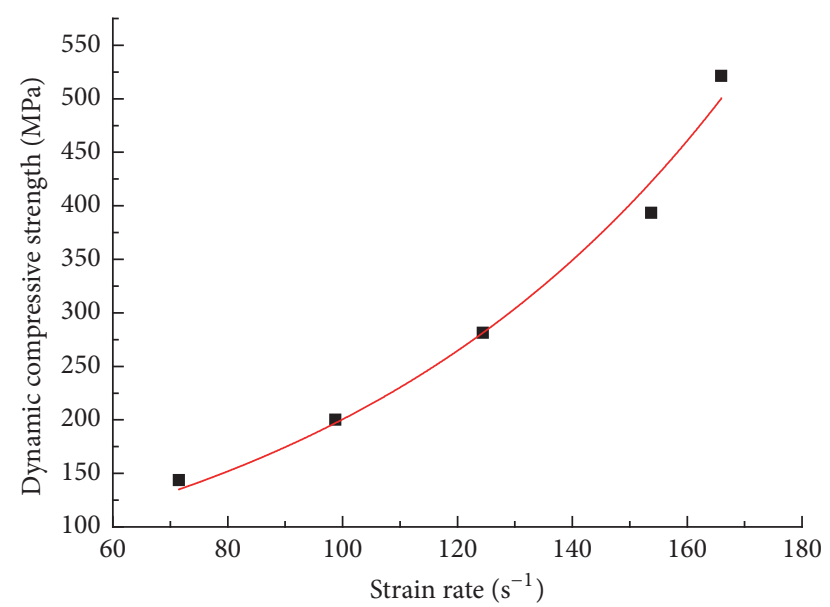

- Experimental data - Fitting curve

FIGURE 9: Relationship between dynamic compressive strength and strain rate.

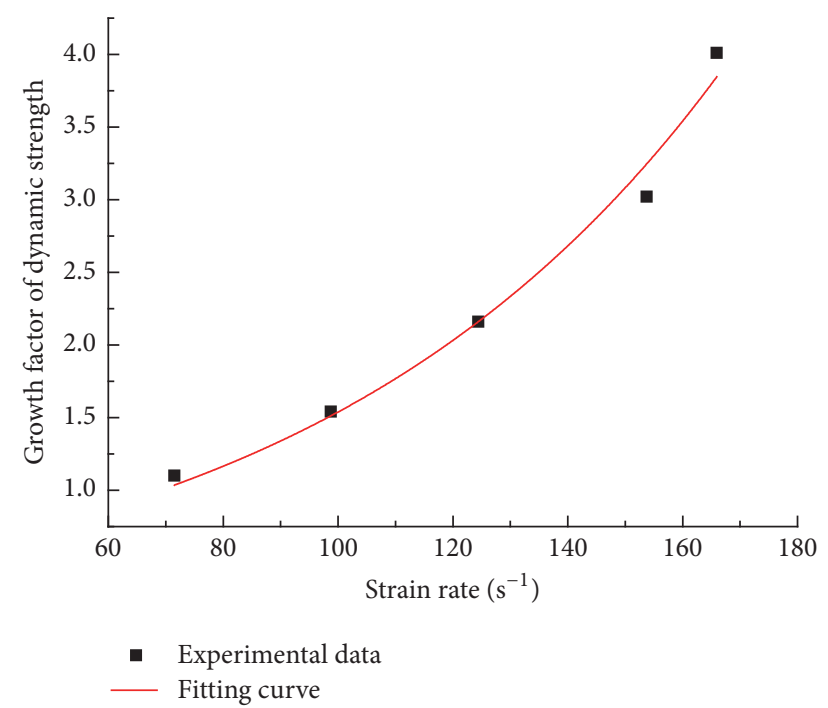

FIGURE 10: The growth factor of dynamic strength versus strain rate.

stress value of the rock material. Therefore, the strength of the material under high strain rate increases with the increasing of strain rate.

The dynamic strength growth factor $I$, which is the ratio of dynamic compressive strength and static compressive strength of limestone samples, is defined to be the index of compressive strength increases of the material under the impact loading. Therefore, the change of dynamic compressive strength of the material with the strain rate can be quantitatively analyzed as shown in Figure 10.

As can be seen from Figure 10, the dynamic strength growth factor $I$ increases with the increasing of strain rate. The lager strain rate will result in a lager increment of impact compressive strength, which indicates that the strain rate sensitivity of the limestone samples increases as the strain rate increases.

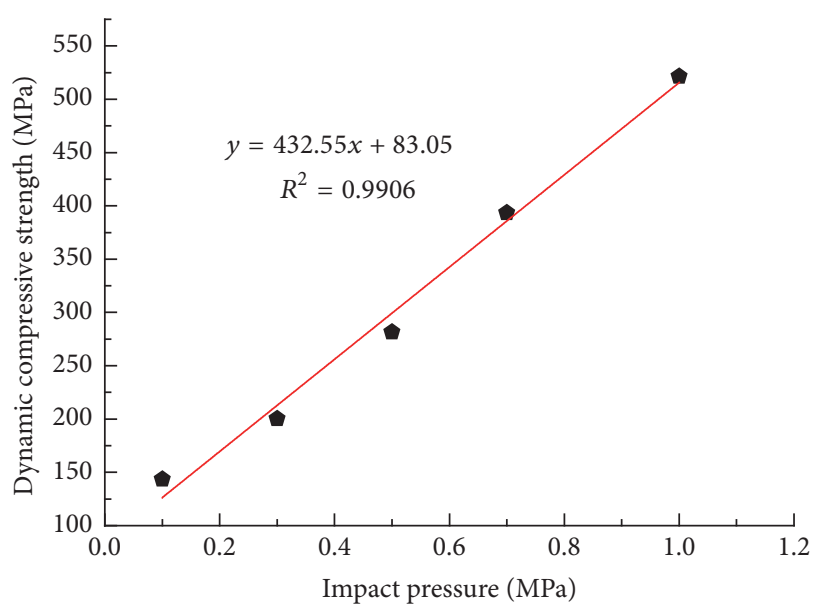

- Experimental data

FIGURE 11: Relationship between dynamic compressive strength and pressure.

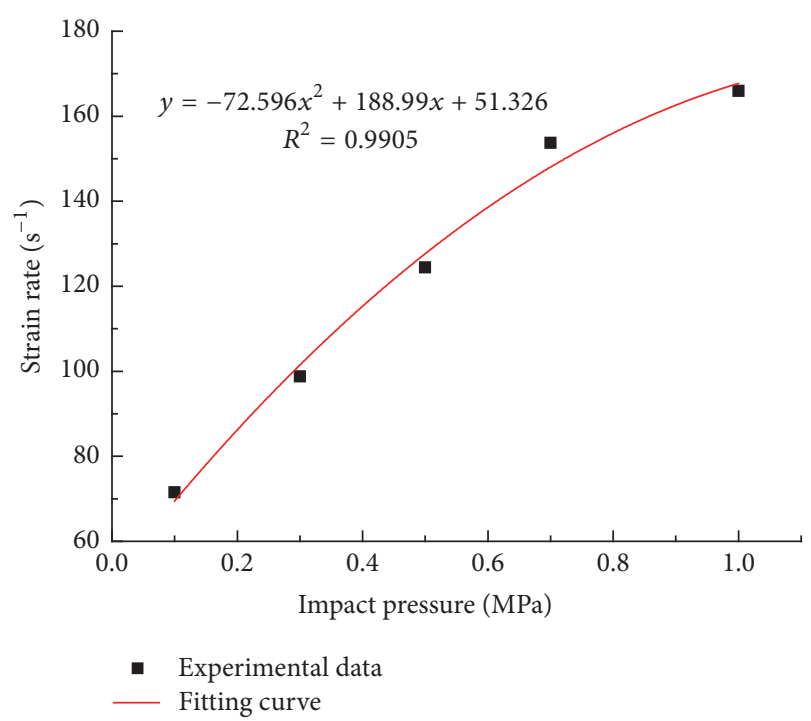

FIGURE 12: Relationship between strain rate and pressure.

Similarly, the dynamic compressive strength, strain rate, and pressure data of the SHPB compression test of limestone samples are all listed; the fitting curves are shown in Figures 11 and 12. Figure 11 shows that the dynamic compressive strength has a linear relationship with the impact pressure, and the correlation is significant. Figure 12 shows that the strain rate increases with the increasing of pressure, but a decreased increment is observed. Because the pressure continued to increase, the impact of a bullet rate increases as well. Although this will make the strain rate time-history curve slope increase, the failure time is correspondingly reduced. Without a long time to enable the continuous increase in strain rate of the samples, the rock samples can also be damaged. 
3.4. Energy Dissipation Characteristics of Limestone under Different Strain Rates. The preceding analysis shows that the failure process of the rock is the energy dissipation process. Therefore, the study on the variation of energy in the experiment will help reflect the variation of rock strength and the essential characteristics of the whole failure process under the external load.

The SHPB uniaxial compression tests are generally considered to satisfy the law of energy conservation, which can be written as follows:

$$
W_{L}(t)=W_{I}(t)-W_{R}(t)-W_{T}(t),
$$

where $W_{I}(t), W_{R}(t)$, and $W_{r}(t)$ are the incident energy, reflected energy, and transmission energy from the beginning of loading to the uninstall process, respectively. $W_{L}(t)$ is the energy absorbed by the sample in the experiment. The calculation formulas are expressed as follows:

$$
\begin{aligned}
& W_{I}(t)=E_{0} C_{0} A_{0} \int_{0}^{t} \varepsilon_{I}^{2}(t) d t, \\
& W_{R}(t)=E_{0} C_{0} A_{0} \int_{0}^{t} \varepsilon_{R}^{2}(t) d t, \\
& W_{T}(t)=E_{0} C_{0} A_{0} \int_{0}^{t} \varepsilon_{T}^{2}(t) d t .
\end{aligned}
$$

In order to determine the ability of the material to absorb energy at different strain rates, the concept of energy absorption rate is defined as follows:

$$
\alpha=\frac{W_{L}(t)}{W_{I}(t)} \times 100 \% .
$$

According to the experimental results, the energy characteristic values of limestone specimens under different loading rates are calculated as shown in Table 5 . We can see from Table 5 that the incident energy is relatively close under the same impact pressure. Meanwhile, with the increase of the impact pressure, the incident energy, reflection energy, transmission energy, and absorption energy are significantly increased, while the energy absorption rate decreases.

Figure 13 shows the changes of the time-history curve of limestone when strain rate is $71.50 \mathrm{~s}^{-1}$. Figure 14 shows the relationship curves between the energy changes of the limestone and strain rate under 5 kinds of different strain rates.

As is shown in Figure 13, in the initial stages of experiment, the incident energy, the reflection energy, the transmission energy, and the absorption energy increase with the increasing of the time. When the energy increases to a certain value, the increasing of energy is slowly or even unchanged; namely, the energy no longer increases. The time-history curves of the reflection energy show that the reflection energy increases only at the beginning of the experiment and then basically remains unchanged.

As is shown in Figure 14, the four kinds of energy will increase as the strain rate increases; the increases of incident energy and the transmission energy are significant, while

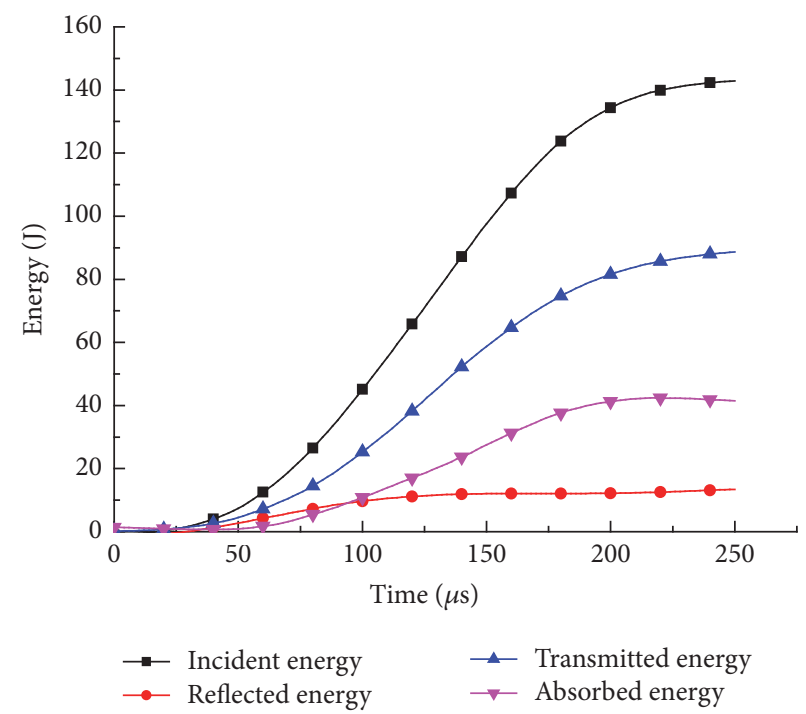

FIGURE 13: Time-history curves of energy of limestone when strain rate is $71.50 \mathrm{~s}^{-1}$.

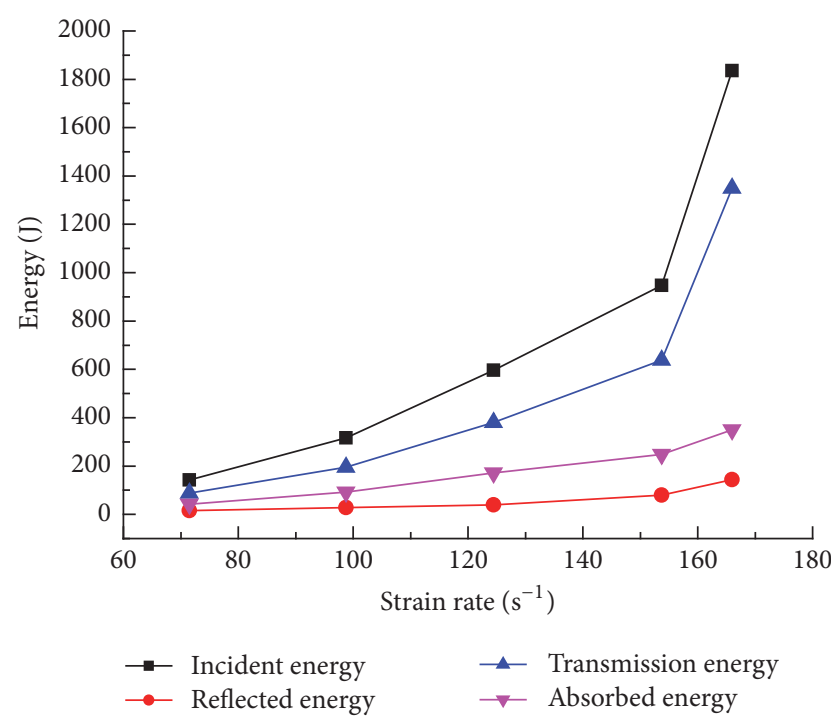

FIgURE 14: The relationships between the energy changes of limestone samples and strain rate.

the increases of reflection and absorption energy are small. When the strain rate is larger than $153.73 \mathrm{~s}^{-1}$, the incident energy, the reflection energy, the transmission energy, and the absorption energy increase sharply. The increases of the incident energy and absorption energy can reach $93.73 \%$ and $41.11 \%$, respectively. In addition, the absorption energy of the sample increases with the increasing of the incident energy, and the cracked degree of corresponding sample increases gradually as shown in Figure 8.

Figure 15 shows the relationship between the energy absorption rate of limestone samples and strain rate. It can be seen that the energy absorption rate decreases from $29.05 \%$ to $19.08 \%$ with the increasing of strain rate and the energy absorption rate decreases with the increasing of strain rate. 
TABLE 5: Energy calculation results of limestone under impact compression.

\begin{tabular}{|c|c|c|c|c|c|c|c|}
\hline $\begin{array}{l}\text { Impact pressure } \\
(\mathrm{MPa})\end{array}$ & $\begin{array}{l}\text { Sample } \\
\text { number }\end{array}$ & $\begin{array}{l}\text { Strain rate } \\
\qquad\left(\mathrm{s}^{-1}\right)\end{array}$ & $\begin{array}{c}\text { Incident energy } \\
(\mathrm{J})\end{array}$ & $\begin{array}{c}\text { Reflection } \\
\text { energy } \\
(\mathrm{J})\end{array}$ & $\begin{array}{c}\text { Transmission } \\
\text { energy } \\
(\mathrm{J}) \\
\end{array}$ & $\begin{array}{l}\text { Absorption } \\
\text { energy } \\
(\mathrm{J})\end{array}$ & $\begin{array}{c}\text { Energy } \\
\text { absorption rate } \\
(\%)\end{array}$ \\
\hline \multirow{2}{*}{0.1} & DCL01-1 & 71.50 & 142.68 & 11.63 & 88.665 & 42.39 & 29.71 \\
\hline & DCL01-2 & 74.67 & 150.87 & 15.77 & 90.84 & 44.26 & 29.34 \\
\hline \multirow{2}{*}{0.3} & DCL02-1 & 98.78 & 316.07 & 28.28 & 195.75 & 92.04 & 29.12 \\
\hline & DCL02-3 & 104.86 & 328.54 & 34.56 & 198.83 & 95.15 & 28.96 \\
\hline \multirow{2}{*}{0.5} & DCL03-1 & 114.69 & 596.54 & 39.53 & 385.76 & 171.25 & 28.71 \\
\hline & DCL03-2 & 124.45 & 578.34 & 35.79 & 383.66 & 158.89 & 27.47 \\
\hline \multirow{2}{*}{0.7} & DCL04-2 & 153.73 & 947.80 & 79.16 & 620.32 & 248.32 & 26.2 \\
\hline & DCL04-3 & 156.21 & 966.65 & 88.43 & 636.46 & 241.76 & 25.01 \\
\hline \multirow{2}{*}{1.0} & DCL05-1 & 165.96 & 1836.19 & 144.2 & 1341.58 & 350.41 & 19.08 \\
\hline & DCL05-3 & 173.72 & 1805.23 & 167.23 & 1312.79 & 324.98 & 18.00 \\
\hline
\end{tabular}

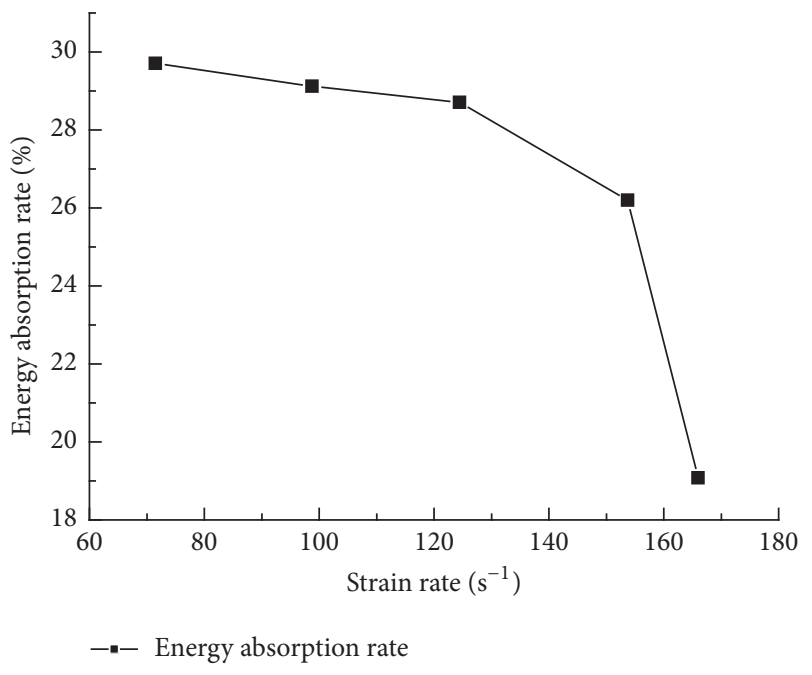

FIGURE 15: The relationship between the energy absorption rate of limestone samples and strain rate.

On one hand, when the strain rate is larger, the incident energy is big enough; the sample already has been destroyed before absorbing enough energy. On the other hand, because of the brittleness of limestone, the internal defects, and the nonuniformity of material, the sample cracks from the existing defect tip and extend along the direction parallel to the compressive stress when subjected to impact loads. Therefore, the effective contact area is significantly reduced and the absorption capacity of the sample is obviously decreased.

\section{Conclusion}

(1) The rubber shaper with the diameter of $5 \mathrm{~mm}$ and the thickness of $2 \mathrm{~mm}$ can effectively modify the stress wave from the high frequency square wave to the half-sine wave with more gentle rising section and smoother waveform.
Compared with no shaper, the rising edge increases by $370.28 \%$ and satisfies the effectiveness of the experiment.

(2) The initial elastic modulus of limestone is not sensitive to the stress rate under the uniaxial compressive load, while the dynamic compressive strength shows a strong strain rate effect, which has an exponential function relation to strain rate and the correlation reaches $99.20 \%$. The dynamic compressive strength of limestone and the strain rate increase with the increasing of the impact pressure, and the strain rate increase is smaller than the increase of impact pressure.

(3) With the increase of strain rate, the fracture degree of samples is significantly increased, which shows a significant strain rate effect. When strain rate is low, the limestone samples are mainly axial splitting failure, while the limestone samples are crushing failure under high strain rate.

(4) At the initial stage of the experiment, the incident energy, the reflection energy, the transmission energy, and the absorption energy increase with the increasing of time. When the energy increases to a certain value, the increase of energy is slow or even unchanged, while the reflection energy increases only in the beginning of the experiment and then remains unchanged. The incident energy and the absorption energy increase with the increasing of strain rate. When the strain rate is larger than $153.73 \mathrm{~s}^{-1}$, the incident energy, the reflection energy, the transmission energy, and the absorption energy all increase dramatically; however, the energy absorption rate decreases with the increasing of strain rate.

\section{Competing Interests}

The authors declare that there are no competing interests regarding the publication of this article.

\section{Acknowledgments}

The authors are grateful to the Traffic Technology Fund of Guizhou Province of China (no. 2015122046). 


\section{References}

[1] Ö. Aydan and H. Kumsar, "An experimental and theoretical approach on the modeling of sliding response of rock wedges under dynamic loading," Rock Mechanics and Rock Engineering, vol. 43, no. 6, pp. 821-830, 2010.

[2] M. Tao, X. Li, and D. Li, "Rock failure induced by dynamic unloading under 3D stress state," Theoretical \& Applied Fracture Mechanics, vol. 65, no. 3, pp. 47-54, 2013.

[3] G. Zhao, L. Xie, and X. Meng, "A damage-based constitutive model for rock under impacting load," International Journal of Mining Science \& Technology, vol. 24, no. 4, pp. 505-511, 2014.

[4] Q. B. Zhang and J. Zhao, "A review of dynamic experimental techniques and mechanical behaviour of rock materials," Rock Mechanics \& Rock Engineering, vol. 47, no. 4, pp. 1411-1478, 2014.

[5] E. D. H. Davies and S. C. Hunter, "The dynamic compression testing of solids by the method of the split Hopkinson pressure bar," Journal of the Mechanics \& Physics of Solids, vol. 11, no. 3, pp. 155-179, 1963.

[6] Q. Z. Wang, W. Li, and H. P. Xie, "Dynamic split tensile test of Flattened Brazilian Disc of rock with SHPB setup," Mechanics of Materials, vol. 41, no. 3, pp. 252-260, 2009.

[7] C. E. Frantz, P. S. Follansbee, and W. J. Wright, "Experimental techniques with the split Hopkinson bar," in Proceedings of the International Conference on High Energy Rate Fabrication, pp. 17-21, San Antonio, Tex, USA, June 1984.

[8] L. Xibing and G. Desheng, "On the reasonable loading stress waveforms determined by dynamic stress-strain curves of rocks by SHPB," Journal of Explosion and Shock Waves, vol. 13, no. 2, pp. 125-131, 1993 (Chinese).

[9] Z. Zhou, X. Li, A. Liu, and Y. Zou, "Stress uniformity of split Hopkinson pressure bar under half-sine wave loads," International Journal of Rock Mechanics and Mining Sciences, vol. 48, no. 4, pp. 697-701, 2011.

[10] M. Friedman, R. D. Perkins, and S. J. Green, "Observation of brittle-deformation features at the maximum stress of westerly granite and solenhofen limestone," International Journal of Rock Mechanics \& Mining Sciences \& Geomechanics Abstracts, vol. 7, no. 3, pp. 297-302, 1970.

[11] W. Janach, "The role of bulking in brittle failure of rocks under rapid compression," International Journal of Rock Mechanics \& Mining Sciences and, vol. 13, no. 6, pp. 177-186, 1976.

[12] M. M. Leblanc and D. H. Lassila, "Dynamic tensile testing of sheet material using the split-hopkinson bar technique," Experimental Techniques, vol. 17, no. 1, pp. 37-42, 1993.

[13] H. B. Li, J. Zhao, and T. J. Li, "Micromechanical modelling of the mechanical properties of a granite under dynamic uniaxial compressive loads," International Journal of Rock Mechanics \& Mining Sciences, vol. 37, no. 6, pp. 923-935, 2000.

[14] H. Meng and Q. M. Li, "Correlation between the accuracy of a SHPB test and the stress uniformity based on numerical experiments," International Journal of Impact Engineering, vol. 28, no. 5, pp. 537-555, 2003.

[15] X. Li, Z. Zhou, Z. Ye et al., "Study of rock mechanical characteristics under coupled static and dynamic loads," Chinese Journal of Rock Mechanics and Engineering, vol. 27, no. 7, pp. 1387-1395, 2008 (Chinese).

[16] J. Liu, J. Xu, X. Lu, L. Zhang, and Z. Wang, "Experimental study on dynamic mechanical properties of amphibolites under impact compressive loading," Chinese Journal of Rock Mechanics and Engineering, vol. 28, no. 10, pp. 2113-2120, 2009 (Chinese).
[17] J. Zou and S. Li, “Theoretical solution for displacement and stress in strain-softening surrounding rock under hydraulicmechanical coupling," Science China Technological Sciences, vol. 58, no. 8, pp. 1401-1413, 2015.

[18] J.-F. Zou, S.-S. Li, Y. Xu, H.-C. Dan, and L.-H. Zhao, “Theoretical solutions for a circular opening in an elastic-brittle-plastic rock mass incorporating the out-of-plane stress and seepage force," KSCE Journal of Civil Engineering, vol. 20, no. 2, pp. 687-701, 2016.

[19] Z. Jin-Feng and S. Yu, "Theoretical solutions of a circular tunnel with the influence of the out-of-plane stress based on the generalized hoek-brown failure criterion," International Journal of Geomechanics, vol. 16, no. 3, Article ID 06015006, 2016.

[20] J. F. Zou and Z. He, "Numerical approach for strain-softening rock with axial stress," Proceedings of the Institution of Civil Engineers-Geotechnical Engineering, vol. 169, no. 3, pp. 276290, 2016.

[21] J. F. Zou, Z. Q. Xia, and H. C. Dan, "Theoretical solutions for displacement and stress of a circular opening reinforced by grouted rock bolt," Geomechanics and Engineering, vol. 11, no. 3, pp. 439-455, 2016.

[22] J. Zou and S. Zuo, "Similarity solution for the synchronous grouting of shield tunnel under the vertical non-axisymmetric displacement boundary condition," Advances in Applied Mathematics and Mechanics, vol. 9, no. 1, pp. 205-232, 2017.

[23] D. J. Frew, M. J. Forrestal, and W. Chen, "Pulse shaping techniques for testing brittle materials with a split Hopkinson pressure bar," Experimental Mechanics, vol. 42, no. 1, pp. 93-106, 2002.

[24] X. B. Li, T. S. Lok, J. Zhao et al., "Oscillation elimination in the Hopkinson bar apparatus and resultant complete dynamic stress-strain curves for rocks," International Journal of Rock Mechanics \& Mining Sciences, vol. 37, no. 7, pp. 1055-1060, 2000.

[25] W. Janach, "The role of bulking in brittle failure of rocks under rapid compression," International Journal of Rock Mechanics \& Mining Science \& Geomechanics Abstracts, vol. 13, no. 6, pp. 177186, 1976.

[26] W. F. Brace and A. H. Jones, "Comparison of uniaxial deformation in shock and static loading of three rocks," Journal of Geophysical Research, vol. 76, no. 20, pp. 4913-4921, 1971. 


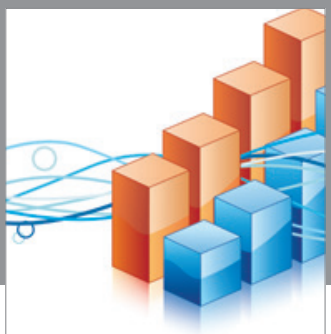

Advances in

Operations Research

vatem alat4

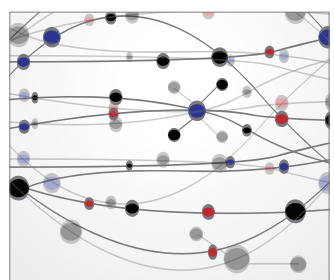

\section{The Scientific} World Journal
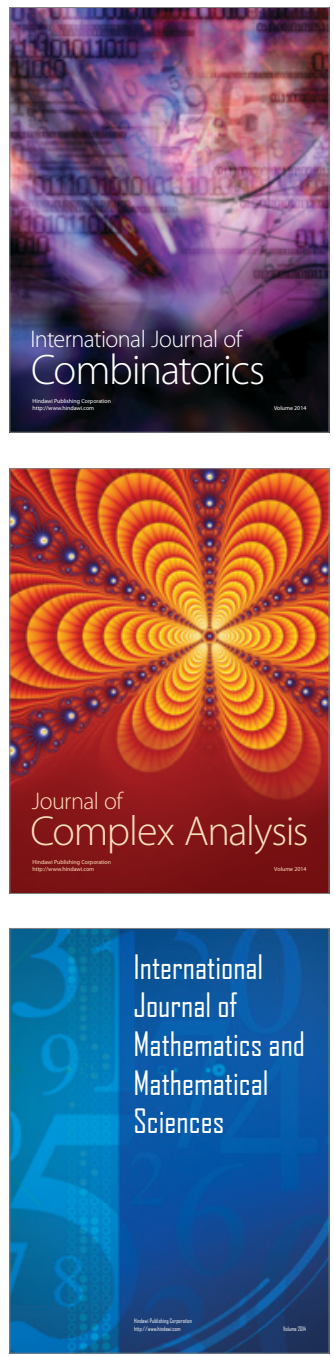
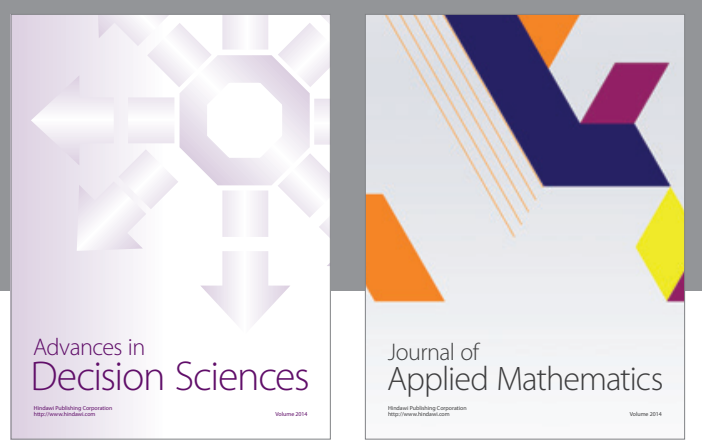

Algebra

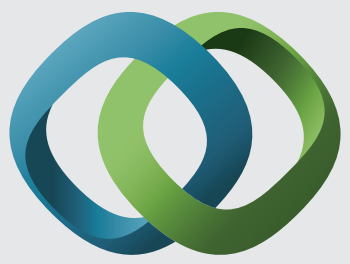

\section{Hindawi}

Submit your manuscripts at

http://www.hindawi.com
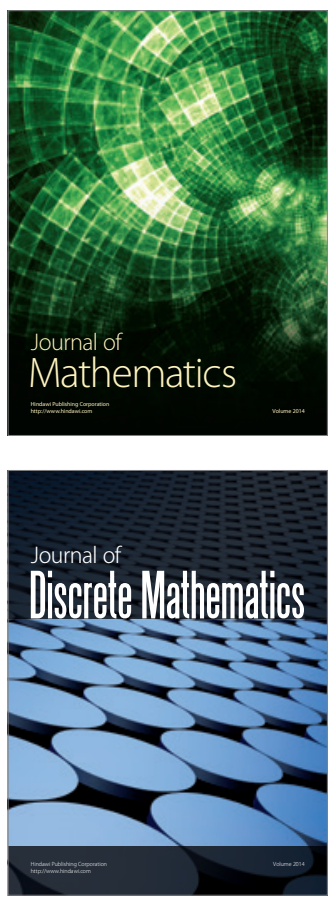

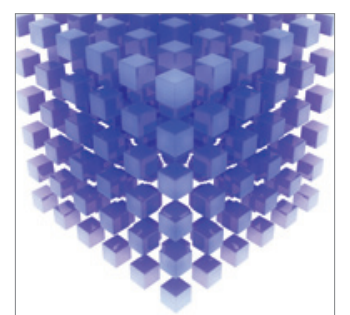

Mathematical Problems in Engineering
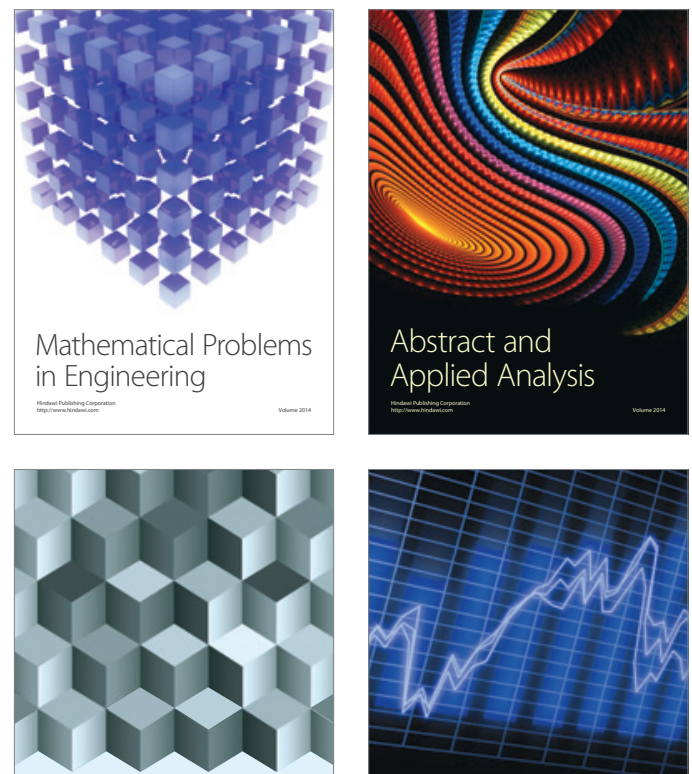

Journal of

Function Spaces

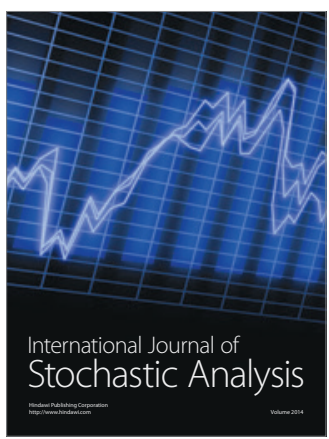

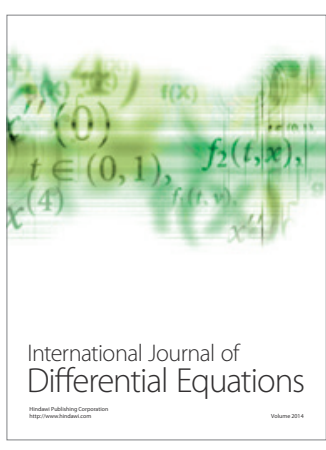
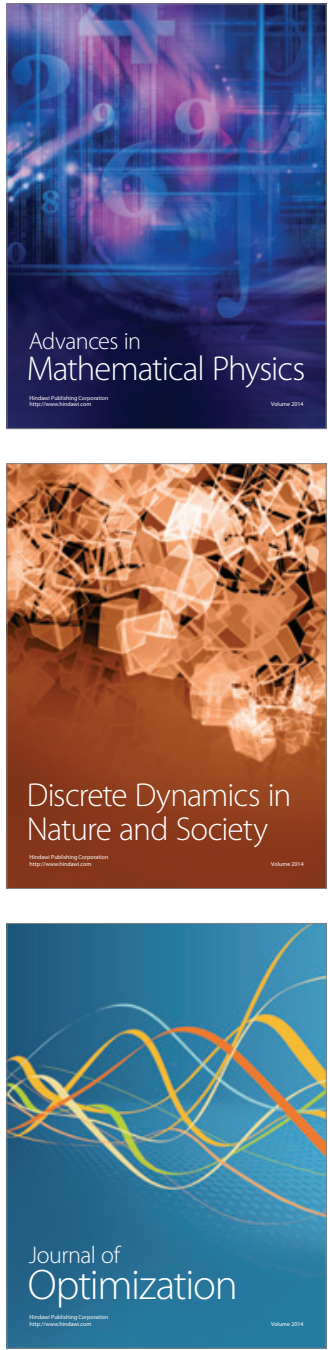